\title{
Seizures in a Pediatric Patient with a Tiagabine Overdose
}

\author{
Ziad N. Kazzi, MD ${ }^{\mathrm{a}}$, Chris C. Jones, Pharm D ${ }^{\mathrm{b}}$, Brent W. Morgan, MD \\ a Department of Emergency Medicine, University of Alabama at Birmingham \\ b Georgia Poison Center, Atlanta, GA \\ c Department of Emergency Medicine, Emory University, Atlanta, GA
}

\begin{abstract}
Introduction: Tiagabine (TGB) is a novel antiepileptic that decreases GABA uptake. The literature contains one report of an adult with epilepsy who ingested up to 1 gram of TGB and developed status epilepticus. We reported on a pediatric patient who ingested significantly less TGB but still developed tonic-clonic seizures.

Case report: A previously healthy, $13 \mathrm{~kg}$, two-year-old girl developed generalized tonic-clonic seizure activity at home approximately 1 hour after ingesting $90 \mathrm{mg}$ of her grandmother's TGB (forty five $2 \mathrm{mg}$ tablets). At the hospital she had two 5 minute seizures at 1.5 and 3.5 hours post ingestion. Her serum TGB levels were 530 and $130 \mathrm{ng} / \mathrm{ml}$ approximately 5 and 11 hours post-ingestion (5-70 $\mathrm{ng} / \mathrm{ml}$ trough levels with most probable range for seizure control). She was discharged 27 hours post ingestion, and she was in good condition.
\end{abstract}

Conclusion: An overdose of TGB, a novel anti-epileptic, can cause convulsive seizures.

\section{INTRODUCTION}

Tiagabine (TGB) is a relatively novel antiepileptic that was approved for use by the Food and Drug Administration (FDA) in 1997 as an adjunct agent for the treatment of adults and children more than 12-years-of-age with partial seizures [1]. On 18 February 2005, the FDA issued a warning about the possible occurrence of seizures in non-epileptic patients treated with TGB [2]. We describe the first case of a pediatric patient who developed status epilepticus after the accidental ingestion of TGB.

\section{CASE REPORT}

A previously healthy $13 \mathrm{~kg}$ two-year-old girl was found having generalized tonic-clonic seizure activity. An empty bottle of her grandmother's TGB was found at her side. Forty-five $2 \mathrm{mg}$ tablets were missing. The ingestion probably occurred 30-60 minutes prior to the occurrence of the seizure.

On presentation to the hospital, the girl was afebrile with normal vital signs. Cardiac monitoring did not show any rhythm or morphological abnormalities. The blood glucose and electrolytes were within normal limits. The patient had two generalized tonic-clonic seizures at 1.5 and 3.5 hours post ingestion. Each seizure lasted five minutes, and the patient responded to $0.5 \mathrm{mg}$ of IV lorazepam. The patient was obtunded and did not fully regain consciousness between seizures. Her serum TGB levels were 530 and $130 \mathrm{ng} / \mathrm{ml}$ approximately 5 and 11 hours postingestion (5-70 $\mathrm{ng} / \mathrm{ml}$ trough levels with most probable range for seizure control). Further seizure workup (including imaging) was deferred based on evidence of overdose. The rest of her hospital course was uneventful and she was discharged 27 hours post ingestion, and she was in good condition. No long-term follow up on the patient's condition is available.

Keywords: tiagabine, seizures, overdose, pediatric There was no outside funding of any kind used for this study. Corresponding Author: Ziad N. Kazzi, MD, 625 19th street, JTN 238 Birmingham, AL 35249. Email: zkazzi@uabmc.edu 


\section{DISCUSSION}

In the literature, there currently exist three reported adult cases of overdose. The first patient ingested $320 \mathrm{mg}$ of TGB and $400 \mathrm{mg}$ of phenytoin and presented in coma [7]. After intentional overdose, the second patient presented in status epilepticus on two separate occasions. His seizures were refractory to first line therapies and required phenobarbital coma. His TGB levels were 1870 and $2620 \mathrm{ng} / \mathrm{ml}$ respectively. The amount of TGB ingested during the second admission was estimated to be $1 \mathrm{~g}$ [6]. The third patient (a 46-year-old female patient who possibly ingested up to $72 \mathrm{mg}$ of her own TGB) was confused, non verbal, had facial grimacing, and flexion posturing of her upper extremities. After benzodiazepines, her symptoms resolved within 12 hours of her presentation. Unfortunately, no serum TGB level was obtained [10].

Our patient represents the first reported pediatric case. She ingested significantly less tiagabine than in other case reports (90 mg; $7 \mathrm{mg} / \mathrm{kg}$ ) and still developed status epilepticus.

Gamma-aminobutyric acid (GABA) is known to play an important role in modulating central nervous system (CNS) neuronal firing. One important mechanism is by opening neuronal chloride channels that lead to hyperpolarization of the neuronal cell membrane. Hyperpolarized neurons are less likely to produce or propagate electric waves that would otherwise manifest as convulsions.

Augmenting GABA function is a common mechanism of several antiepileptic drugs such as benzodiazepines and barbiturates (allosteric modulators), baclofen (GABA receptor agonists), GABA reuptake inhibitor (Tiagabine), and GABA transaminase inhibitor (Vigabatrin) [3]. GABA is actively taken up by neuron and astrocyte carrier proteins (including GAT1, GAT4 and BGT-1) and broken down into succinic acid semialdehyde by glutamic acid decarboxylase or repackaged into a vesicle that is released again at the next synaptic transmission [5]. TGB mainly acts by inhibiting GABA reuptake through its action on GAT1 and GAT3 carrier proteins. Moreover, TGB is less specific when binding less specifically to dopamine, serotonin, muscarinic, and glycine receptors [4].

Tiagabine [(R)-N-(4,4-di(3-methylthien-2-yl)but-3-enyl) nipecotic acid hydrochloride] is a derivative of nipecotic acid. TGB is completely and rapidly absorbed after oral ingestion with a peak concentration at 30 to 90 minutes after ingestion. Unlike nipecotic acid, it readily penetrates the CNS secondary to an incorporated lipophylic anchor [12]. The absorption and elimination follows linear kinetics. It is metabolized in the liver mainly through the cytochrome $\mathrm{P} 450$ isoform $3 \mathrm{~A}$ into inactive metabolites that are mainly excreted in feces and urine [12]. Metabolism may be induced, causing the half life to vary between 2 and 9 hours. In general, children metabolize TGB faster, but patients with liver disease more slowly metabolize TGB $[4,11]$.

Phase I and II clinical studies have shown TGB to reduce the frequency of complex partial seizures in patients treated with other anticonvulsants such as valproic acid. The drug was well tolerated, and doses ranged between 12 and $52 \mathrm{mg}$ per day. Reported adverse effects included tiredness, headache, nervousness and difficulty concentrating $[12,16]$.
There are several reports of non-convulsive status epilepticus associated with the therapeutic use of TGB in patients with partial seizures. These patients were on relatively elevated dosages of TGB or had a recent increase in their dosage. They developed EEG findings, some associated with confusion and alteration of consciousness while others had minimal or no clinical findings. The clinical and EEG findings suggested discontinuation of the drug or decrease of the dose $[13,14,15]$.

Recently, the FDA has released a warning based on postmarketing reports about the occurrence of seizures in 59 nonepileptic patients treated with TGB for other indications [2]. The cause of these seizures is unknown. It has been proposed as secondary to the concomitant use of other drugs by non-epileptic patients or due to an inherent difference between the nonepileptic patient population and epileptics.

Similarly, in overdose situations, the mechanism of toxicity of TGB is not known. A study in rats suggests that the epileptic effect may be mediated through other mechanisms in different parts of the CNS such as the thalamus [17]. Other potential mechanisms include TGB stimulation of dopamine, serotonin, or glycine receptors in different areas in the brain. Epileptic effect may occur more frequently in overdose situations where the low affinity of these receptors to TGB is overcome by the elevated levels of CNS TGB.

Management of TGB overdoses is mostly supportive with special attention to the airway. Since TGB's metabolites are excreted in bile, multiple doses of activated charcoal may be useful in large or severe ingestions. Tiagabine did not cause any cardiovascular complications in any of the reported cases but cardiac monitoring is part of the general supportive measure. Intravenous benzodiazepines should be a first line treatment against seizures. Intravenous barbiturates should be reserved for refractory cases.

\section{CONCLUSION}

A variety of antiepileptics are used in patients with psychiatric or other neurological conditions. This increased use may lead to a different adverse effect profile than the one reported in preliminary studies. Tiagabine appears to cause non-convulsive as well as convulsive status epilepticus in a subset of non epileptic and epileptic patients. The FDA's warning is warranted and should be followed by surveillance of frequency and severity of TGB overdoses reported to the American Association of Poison Control Centers (AAPCC).

The authors have no potential conflicts of interest to report.

\section{REFERENCES}

1. FDA Approved Labeling Text dated February 14, 2005 www.fda.gov/cder/foi/label/2005/02064s0141bl.pdf (Accessed May 14th, 2005).

2. FDA medwatch. www.fda.gov/cder/drug/infopage/ tiagabine/tiagabine/default.htm (Accessed May 14th, 2005). 
3. Nielsen EB, Suzdak PD, Andersen KE, Knutsen LJ,

Sonnewald U, Braestrup C. Characterization of tiagabine (NO328), a new potent and selective GABA uptake inhibitor. Eur J

Pharmacol 1991;196 (3):257-266

4. Leach JP, Brodie MJ. Tiagabine. Lancet 1998;351 (9097):203-207

5. Sarup A, Larsson OM, Schousboe A. GABA transporters and GABA-transaminase as drug targets. Current drug targetsCNS and neurological disorders 2003;2 (4):269-277

6. Ostrovskiy D, Spanaki MV, Morris GL III. Tiagabine overdose can induce convulsive status epilepticus. Epilepsia 2002; 43 (7):773-774

7. Leach JP, Stolarek I, Brodie MJ. Deliberate overdose with the novel anticonvulsant tiagabine. Seizure 1995;4 (2):155-157

8. Fitzek S, Hegemann S, Sauner D, Bonsch D, Fitzek C. Drug-induced nonconvulsive status epilepticus with low dose of tiagabine. Epileptic Disorders 2001;3 (3):147-50

9. Shinnar S, Berg AT, Treiman DM, Hauser WA, Hesdorffer DC, Sackellares JC, Leppik I, Sillanpaa M, Sommerville KW. Status epilepticus and tiagabine therapy: review of safety data and epidemiologic comparisons. Epilepsia 2001;42 (3):372-9

10. Cantrell FL, Ritter M, Himes E. Intentional overdose with tiagabine: an unusual clinical presentation. J Emerg Med

2004; 27 (3):271-2
11. Lau AH, Gustavson LE, Sperelakis R, Lam NP, ElShourbagy T, Qian JX, Layden T. Pharmacokinetics and safety of tiagabine in subjects with various degrees of hepatic function. Epilepsia 1997;38 (4):445-51

12. Mengel H. Tiagabine. Epilepsia 1994;5 suppl 5:S81-S84

13. Kellinghaus C, Dziewas R, Ludemann P. Tiagabinerelated non-convulsive status epilepticus in partial epilepsy: three case reports and a review of the literature. Seizure 2002; $11: 243-249$

14. de Borchgrave V, Lienard F, Willemart T, van Rijckevorsel K. Clinical and EEG findings in six patients with altered mental status receiving tiagabine therapy. Epilepsy Behav 2003;4 (3):326-37

15. Balslev T, Uldall P, Buchholt J. Provocation of nonconvulsive status epilepticus by tiagabine in three adolescent patients. European Journal of Paediatric Neurology 2000;4 (4):169-70

16. Leppik IE, Gram L, Deaton R, Sommerville KW. Safety of tiagabine: summary of 53 trials. Epilepsy Res 1999;33 (2-3):235-46

17. Richards DA, Lemos T, Whitton PS, Bowery NG. Extracellular GABA in the ventrolateral thalamus of rats exhibiting spontaneous absence epilepsy. A microdialysis study. Journal of Neurochemistry 1995;65:1674-80 